\title{
Benefits of trenching behavior in the context of an inducible defense
}

Jessica L. E. Chambers • May R. Berenbaum •

Arthur R. Zangerl

Published online: 3 March 2009

(C) Birkhäuser Verlag, Basel/Switzerland 2009

Erratum to: Chemoecology

DOI 10.1007/s00049-007-0371-2

Please note that the first name of the first author is Jessica instead of Jennifer as originally printed.

The online version of the original article can be found under doi:10.1007/s00049-007-0371-2.

J. L. E. Chambers · M. R. Berenbaum · A. R. Zangerl ( $₫)$

Department of Entomology, 320 Morrill Hall,

University of Illinois at Urbana-Champaign,

505 S. Goodwin, Urbana, IL 61801, USA

e-mail: azangerl@life.uiuc.edu 